\title{
Os feminismos como (des)construção dos Direitos Humanos: a importância de filósofas modernas na resistência ao iluminismo misógino
}

\author{
Feminisms as (De)Construction of Human Rights: The importance of the Modern \\ Women Philosophers in Resistance to the Misogynist Enlightenment.
}

\section{Maria Walkíria Cabral* Luiza de Souza Lima Macedo**}

\begin{abstract}
RESUMO: O presente artigo tem como objetivo apresentar brevemente a trajetória de Olympe De Gouges e Mary Wollstonecraft e a importância dos processos de desconstrução feministas no enfrentamento à dominação patriarcal no direito e, consequentemente na sociedade ocidental. Nesse sentido, o artigo busca mostrar como as obras das filósofas modernas são relevantes para o desenvolvimento dos feminismos atuais, pois marcaram o contexto do Iluminismo, se contrapondo aos atos e teorias misóginas perpetrados por aqueles que, até hoje, são tidos como referência na construção histórica dos direitos humanos.

Palavras-chaves: Feminismo, Direitos Humanos, Iluminismo.
\end{abstract}

\begin{abstract}
This article aims to briefly present the trajectory of Olympe De Gouges and Mary Wollstonecraft and the importance of feminist deconstruction processes in confronting patriarchal domination in law and, consequently, in Western society. In this sense, the article seeks to show how the works of modern feminists philosophers are relevant for the development of current feminisms, as they marked the context of the Enlightenment, opposing the misogynistic acts and theories perpetrated by those who, to this day, are considered as a reference in the historical construction of human rights.
\end{abstract}

Keywords: Feminism, Human Rights, Enlightenment.

\section{INTRODUÇÃO}

Muito se fala da contribuição de alguns pensadores iluministas na construção dos direitos individuais, base do Estado de Direito, porém pouco se fala em relação ao ideal misógino que embalou as teorias desses pensadores e, menos ainda, como filósofas e escritoras da época já denunciavam a misoginia contida nos escritos desses pensadores.

\footnotetext{
* Professora Adjunta do Instituto de Pesquisa em Planejamento Urbano e Regional da Universidade Federal do Rio de Janeiro (IPPUR/UFRJ). Coordenadora do Núcleo de Pesquisa em Gênero, Espaço e Políticas Públicas (NUGEPP/UFRJ). Pesquisadora do Laboratório Filosofias do Tempo do Agora (LAFITA/UFRJ). Doutora e Mestra em Direito (PUC Minas). Filósofa e Advogada. E-mail: mwcabral@ippur.ufrj.br ORCID: http://orcid.org/0000-0002-4963-3816

** Graduação em História pela Universidade Federal de Minas Gerais e Mestrado em Lazer pela Universidade Federal de Minas Gerais (2020). Tem experiência na área de Educação, com ênfase em Mediação em Museus, atuando principalmente nos seguintes temas: museu, educativo, educação, educação não formal e espaço não formal de educação. É membro do Núcleo de Pesquisa em Gênero, Espaço e Políticas Públicas - NUGEPP (UFRJ). E-mail: luizasI.macedo@gmail.com ORCID: http://orcid.org/0000-0002-40092873
} 
O presente trabalho organiza alguns debates, relativos ao período da formação dos ideais Iluministas, essenciais na consolidação de uma Teoria Feminista do Direito, que busca auxiliar ${ }^{1}$ na desconstrução das bases do pensamento moderno e, consequentemente, das teorias jurídicas clássicas. Entendemos como necessário rever o apagamento histórico pelo qual passaram (e ainda passam) as filósofas iluministas da Modernidade, ação importante para a construção atual de uma Teoria Feminista do Direito, assim como para o entendimento atual dos feminismos.

Para tanto, optou-se aqui por percorrer os caminhos iniciais dos Direitos Humanos, a partir das obras de duas importantes filósofas feminista da época moderna, Olympe De Gouges e Mary Wollstonecraft, atualmente consideradas por algumas como feminismo liberal (entendido aqui como primeira onda feminista), mas que estarão presentes na prática política de todas as épocas e vertentes ${ }^{2}$.

Entendemos que conhecer o desenvolvimento histórico dos feminismos é importante para se refletir e questionar a lógica clássica e patriarcal do Direito, construída por certos discursos, que que se apresentam como em prol das mulheres, mas que na prática de fato não o são, pois possuem raízes em teorias filosóficas claramente excludentes e opressoras.

Cabe ressaltar que, quando se fala acerca da narrativa moderna dos direitos das mulheres, o trabalho que se tem pela frente é de descrição e análise do surgimento das teorias feministas que irão se concretizar pelas vozes das filósofas ${ }^{3}$. Vale salientar, ainda, que aqui tratamos de um contexto específico, não sendo possível abarcar toda a miríade de personalidades e pensamentos do período moderno, mais especificamente do contexto eurocêntrico.

Dessa forma, o nosso objetivo aqui é apresentar um possível momento de surgimento da filosofia política feminista ocidental, que irá se ramificar em tantos outros caminhos ao longo da história da humanidade, de forma a reafirmar que feminismo não é tema de moda ou assunto complementar que permeia outros, mas, sim, uma filosofia de debate e resistência, historicamente silenciada pelo patriarcado ocidental.

\section{O FEMINISMO E O ILUMINISMO MISÓGINO.}

Não é possível e nem interessante datar historicamente quando surge o feminismo. No entanto, poderíamos dizer que ações atualmente entendidas como femininas sempre existiram, a partir do momento que qualquer mulher se contrapôs a uma situação concreta, particular ou não, de opressão social pelo simples fato de ser mulher, mas o momento histórico em que isso ocorreu não é possível determinar e acreditamos até que esse não seja o ponto crucial para uma abordagem feminista sobre a história de lutas das sujeitas excluídas pelo patriarcado.

É possível, no entanto - e, diríamos, até mesmo necessário - retomar importantes posicionamentos de filosofia política desenvolvidos por mulheres que compõem, não exatamente um

\footnotetext{
${ }^{1}$ Entendemos que se trata de um auxílio, pois a desconstrução só se consagra enquanto tal quando instituída por meio da ação política.

20 feminismo, em suas várias vertentes, não se limita a uma corrente de pensamento, mas sim, combina a produção intelectual questionadora à ação, à militância pelos direitos de todos, sob uma perspectiva de gênero, isto é, sob a análise da formação da sociedade a partir da dominação masculina.

3 No Brasil, o feminismo político dessa geração pode ser encontrado formalmente nas ideias e pela história de Nísia Floresta (1810-1885), que chegou a publicar uma tradução livre de uma das obras de Mary WolIstonecraft, sob o título de "Direito das mulheres e a injustiça dos homens", com publicação mais recente pela Editora Cortez, em 1989. ,
} 
marco inicial, mas o que convencionou-se chamar de primeira onda feminista.

Mesmo que haja controvérsias e novas concepções em relação ao uso da expressão, primeira onda feminista é o termo mais usado para designar o momento histórico em que as ideias de filósofas e ativistas estavam sendo organizadas e sistematizadas, conforme o novo modelo de racionalidade, que segue reverberando na atualidade (SANTOS, 2014; TARRANT, 2006). Ela não se inicia exatamente na Modernidade, visto que importantes obras sobre os direitos das mulheres podem ser encontradas já no medievo, com Christine de Pizan $(1340-1430)^{4}$, que perceberá a estrutura opressora da sociedade, passando a reivindicar o direito à educação e o alargamento do corpo cívico, como forma de libertação das mulheres, ou até mesmo antes dela.

$\mathrm{Na}$ Era Moderna, reivindicações semelhantes às de Pizan aparecem como teoria política em uma série de discursos importantes, dentre eles, os discursos de três mulheres que lutaram por uma sociedade menos opressora, que garantisse mais oportunidades às mulheres.

Marie Gournay (1565 - 1645) defendeu a igualdade entre homens e mulheres, principalmente em relação à educação, demonstrando que se recebessem a mesma educação, a igualdade se realizaria mais facilmente.

Olympe de Gouges (1748 - 1793) dizia que "se uma mulher pode subir ao cadafalso, ela também pode subir à tribuna". Morreu por ter escrito a "Declaração dos direitos da mulher e da cidadã" em oposição à "Declaração do Homem e do Cidadão", construída por homens dentro de suas perspectivas limitadas e limitantes.

A obra de Mary Wollstonecraft (1759 - 1795), “A Reivindicação dos Direitos das Mulheres” (1792:2016), também marca o cenário político feminista da época, ao apresentar não apenas as reivindicações por esses direitos, mas atestações quanto aos discursos machistas de sua época, a exemplo das críticas que faz a Jean Jacques Rousseau, participando da arena de debate políticofilosófico.

Dentre as mulheres do período iluminista, destacamos aqui os trabalhos de Olympe de Gouges e Mary Wollstonecraft ${ }^{5}$, por desempenharem papel fundamental para a construção da teoria feminista enquanto teoria filosófica, política e jurídica.

\subsection{O discurso dos Direitos do Homem como ferramenta de silenciamento das mulheres.}

As Revoluções Burguesas foram o palco do desenvolvimento de grandes teorias políticas modernas e, assim, também da teoria política feminista moderna. Especialmente na Revolução

\footnotetext{
${ }^{4}$ Pode-se dizer que a filosofia moderna marca o surgimento do feminismo como discurso filosófico a partir de documentos que fomentaram intelectualmente os movimentos das mulheres na luta por direitos., No entanto, é importante lembrar que esse movimento já estava sendo construído ao longo da História, com mulheres silenciadas pela história oficial, como por exemplo Christine de Pizan,, tendo escrito nove tratados sobre política. Cary Nederman (2005), entende que apesar de sua importância intelectual, Christine "passa despercebida" possivelmente em razão de seu gênero. Maria Simone M. Nogueira (2015), por sua vez, descreverá sua atuação como transgressora em três níveis: de gênero, contra a ortodoxia da lgreja e transgressão da relação humano e divino ao aproximar afetividade com intelecção. Apesar do apagamento histórico, a participação das mulheres, principalmente em fins da Idade Média, é notória. . "Nesse contexto conturbado, muitas mulheres levantaram sua voz e, portanto, possuem uma influência político-religiosa importante.

5 Junto das duas filósofas iluministas estavam também mulheres militantes e grandes personagens dessa história em que os homens insistem em forçosamente protagonizar. Marie de Gournay, Madame Roland, Madame Helvetius, Madame de Condorcet, Théroigne de Méricourt e Claire Lacombe são mais alguns nomes de mulheres que lutaram no campo político da época, para que fossem ouvidas (ROVERE, 2019; DALLARI, 2016)
} 
Francesa, os burgueses ${ }^{6}$ receberam apoio direto do movimento dos trabalhadores, que já se organizava contra os privilégios da aristocracia e exigia melhores condições de trabalho, e do movimento das mulheres, que compunha o coro de exigência de condições de vida digna. O que nem os trabalhadores, nem as mulheres se atentaram foi para o fato de que estavam sendo conduzidos pela burguesia, que logo os excluiria, após a tomada de poder. Para além dessa questão de classes, as mulheres participantes do movimento ainda foram excluídas na produção histórica. Segundo Scott (1995), historiadores as mantinham à margem da escrita histórica sobre economia e política, por exemplo.

Não foi suficiente para os(as) historiadores(as) das mulheres provar ou que as mulheres tiveram uma história ou que as mulheres participaram das mudanças políticas principais da civilização ocidental. (...) No que diz respeito à participação das mulheres na História e a reação foi um interesse mínimo no melhor dos casos ("minha compreensão da Revolução Francesa não mudou quando eu descobri que as mulheres participaram dela") (SCOT"T, 1995, p. 74).

Olympe de Gouges, pseudônimo de Marie Gouze, nasceu em 1748, na cidade de Montauban, na França. Ao longo de sua vida, a filósofa se dedicou a questionar o status quo, apoiou a Revolução Francesa por acreditar na possibilidade de mudança, mas foi silenciada quando buscou incluir as mulheres na condição de seres humanos. Guilhotinada no dia 3 de novembro $1793^{7}$, aos 45 anos, De Gouges teve a própria vida marcada pela força do patriarcado nas esferas pública e privada (DE GOUGES, 2020; ROVERE, 2019; DALLARI, 2016).

De Gouges era fruto de um relacionamento extraconjugal de uma mulher comum com um homem da nobreza local, autor de peças de teatro. O nome de seu pai acabou por lhe garantir acesso à nobreza francesa e aos estudos primários, assim como conhecimentos específicos sobre o teatro. Em sua cidade natal, Olympe de Gouges não se dava conta da opressão das mulheres, talvez em razão da convivência com mulheres fortes, chefes de seus lares, como sua mãe por exemplo, que fugia à regra do que se entendia como papel de mulheres.

Após enviuvar-se de um curto casamento (1765 - 1766), De Gouges conheceu Jacques Biétrix de Rozières (1767) e se mudou para Paris em 1770. Na cidade luz, De Gouges, passou a conhecer uma outra realidade que, aos poucos, começou a questionar (ROVERE, 2019; DALLARI, 2016).

O encontro de Olympe de Gouges com as causas pelas quais morreu não se deu rapidamente. Durante certo tempo de sua estadia em Paris, De Gouges se relacionou com a aristocracia francesa em razão das suas atividades teatrais e com o apoio de seu pai (considerado um "padrinho", visto que De Gouges não era filha nascida da relação matrimonial), o dramaturgo Lefranc de Pompignan (ROVERE, 2019).

Com o tempo, De Gouges passou a perceber algumas injustiças, primeiro com relação às mulheres no âmbito do teatro, depois nas classes trabalhadores como um todo. Olympe de Gouges passou, então, a escrever os chamados "affiches" para se manifestar contra as opressões que passou a perceber:

\footnotetext{
6 É importante pontuar que o intuito da burguesia, com as revoluções, nunca foi de igualdade e equidade entre todos e todas, mas sim de conquistar o lugar nos altos estratos da sociedade, uma vez que não possuíam sangue nobre, mas detinham o poder econômico, que nesse momento começa a se concentrar nos meios urbanos e na economia fabril e não mais na propriedade rural (HOBSBAWM, 1977).

${ }^{7}$ Quinze dias antes, a mulher guilhotinada havia sido a rainha Maria Antonieta e cinco dias depois de Olympe, guilhotinaram Madame Roland (DALLARI, 2016).
} 
Com efeito, paralelamente às atividades sociais em ambientes mais luxuosos, ela foi revelando e expondo seu talento de comunicadora e, valendo-se de um meio então em voga na cidade de Paris, passou a escrever cartazes, os "affiches", que mandava imprimir e afixar nos muros das cidades, sobre os mais variados temas, já adotando posições críticas e propondo a correção das injustiças sociais (DALLARI, 2016, p. 113)

Suas peças, verdadeiros panfletos políticos. denunciaram a venda e a exploração de escravos (L'esclavage de noir, 1785; Le Marché des noir, 1790), e o confinamento das mulheres (Le Couvent ou les voeux forcés, 1790), encorajando, na ocasião, o patriotismo (Les Democrates et les Aristocrates; Le Temps et la liberté, 1790) (ROVERE, 2019, p. 247)

Como já apontado, a filósofa está inserida no contexto das revoluções burguesas, mais especificamente da Revolução Francesa, de onde é fruto a Declaração dos Direitos do Homem e do Cidadão, primeiro documento formal com os direitos fundamentais da burguesia, quais sejam, liberdade, propriedade e participação no governo. Um pouco antes, em 1776, no Estado da Virgínia, posteriormente parte dos Estados Unidos da América, foi feita a Declaração de Direitos tendo a liberdade como direito natural do homem ${ }^{8}$.

Com isso, De Gouges percebe que apenas os homens tiveram algum benefício, o que fez com que a luta contra a opressão às mulheres, em especial as pobres, tomasse um caráter primordial em seus manifestos.

Cabe lembrar que De Gouges recebeu grande influência o marquês de Condocert, iluminista e revolucionário que, dentre outras contribuições, foi defensor do sufrágio feminino (NYE, 1995), o que indica que as exigências pela igualdade entre homens e mulheres faziam parte do discurso de alguns teóricos iluministas, em contraponto, às posturas naturalistas (machistas) de Rousseau, por exemplo.

Dessa forma, Olympe de Gouges, que se dedicou ao ideal iluminista revolucionário até perceber que havia algo errado, não se conformou com a diferenciação que os homens de sua época faziam em relação às mulheres, e registrou seu descontentamento na obra intitulada "A Declaração dos Direitos da Mulher e da Cidadã".

\begin{abstract}
Mulher, acorde; o rebate da razão se faz ouvir em todo universo, tome conhecimento de teus direitos [...] O homem escravo multiplicou suas forças, teve necessidade de recorrer às tuas para romper os grilhões. Libertado, ele tornou-se injusto em relação às suas companheiras. Ó, mulheres! Mulheres, quando vocês deixarão de ser cegas? Quais são as vantagens que vocês obtiveram da Revolução? Um desprezo mais acentuado, um desdém mais assinalado (DE GOUGES, 2016, p. 162-163)
\end{abstract}

Suas exigências não foram apenas uma paródia literária da Declaração do Homem, nem uma tentativa de reverter a ordem da opressão, colocando mulheres em posição superior. A filósofa já analisava a situação que estava se formando com o avanço dos iluministas no poder, que mais tarde culminou, não apenas em sua morte na guilhotina, mas também no fechamento dos clubes das mulheres (1793), na proibição da atividade política para as mulheres (1795) e no Código Napoleônico (1804) que colocou a mulher em condição jurídica inferior aos homens (ROVERE,

\footnotetext{
${ }^{8}$ Cabe lembrar aqui que os EUA que ali se formavam nada mais eram do que uma recém ex-colônia inglesa, local onde as mulheres não tinham direitos de cidadã, ou seja, os EUA repetiam suas origens na nova "Declaração de Direitos".
} 
2019).

\subsection{Mary Wollstonecraft como símbolo da resistência à época Rousseau?}

Enquanto Olympe de Gouges liderava as críticas na França, a filósofa e escritora inglesa Mary Wollstonecraft marcava o auge do feminismo da primeira onda na Inglaterra, vivendo uma vida coerente com seus escritos e demandas filosóficas, seguindo seus ideais com lutas pessoais e políticas.

Em que pese a existência das filósofas citadas anteriormente, Maria Lygia Quartim de Moraes (2016) é categórica ao afirmar que a obra da filósofa inglesa pode ser considerada o documento fundador dos feminismos. Em certa medida, Maria Lygia tem razão. A obra pode ser um marco inicial para os feminismos, não pelo fato exclusivo de ser opor à realidade machista, luta já iniciada por Christine, Gournay, De Gouges e outras tantas, mas por marcar o início de uma análise crítica acerca de toda a estrutura social patriarcal, principalmente, analisando como as mulheres podem ser responsáveis pela manutenção do status quo.

Espero que meu próprio sexo me desculpe caso eu trate as mulheres como criaturas racionais, em vez de adular suas graças fascinantes e considerá-las como se estivessem em um estado de perpétua infância, incapazes de ficar sozinhas. Sinceramente, desejo mostrar em que consistem as verdadeiras dignidade e felicidade humanas. Desejo persuadir as mulheres a se esforçarem para adquirir força tanto da mente quanto do corpo e convencê-las de que as frases suaves, a susceptibilidade do coração, a delicadeza dos sentimentos e o gosto refinado são quase sinônimos de epítetos de fraqueza, e de que os seres que são apenas objeto de piedade e daquela espécie de amor que, por definição, lhe é próxima logo se tornarão alvo de desprezo (WOLLSTONECRAFT, 2016, p. 27)

Wollstonecraft irá criticar a estrutura social da romantização das relações e, como uma feminista, suas ideias não ficariam apenas na teoria. Apaixonada por Henry Fuseli, homem casado com quem teve um relacionamento, Mary Wollstonecraft chegou a sugerir à esposa do intelectual que dividissem o marido, assumindo assim o papel ativo de sujeito do desejo e não mais objeto. (MORAES, 2016)

Um importante dado da biografia da filósofa inglesa, mas pouco divulgado, é que ela foi mãe de Mary Shelly, a famosa autora de Frankenstein. Wollstonecraft foi também esposa e possuía sonhos comuns aos de outras mulheres de sua época, como o de ser escritora e viver sua vida em família ao lado do homem que escolhesse para viver. No entanto, como a maioria as mulheres de todas as épocas, a filósofa feminista experimentou o céu e o inferno de ser mulher, passando a perceber que era preciso falar das responsabilidades das mulheres na construção de seus direitos. (MORAES, 2016).

Em 1774, Wollstonecraft fundou uma escola em Newington Green, na região norte de Londres, onde se localizava uma comunidade rural de pensadores livres cuja origem se dera com os não conformistas e dissidentes ingleses no século anterior. Foi a partir dessa experiência no

\footnotetext{
9 Em Gramatologia, Jacques Derrida (2013) considerou a época do surgimento da razão ocidental, como a época Rousseau. Atribuir esse momento histórico (que permanece até a atualidade, ao menos no que tange à lógica jurídica) a Jean Jacques Rousseau não foi por escolha aleatória, dentre os filósofos políticos da época da formação do Estado de Direito. Rousseau, como iremos mostrar, foi declaradamente contra qualquer possibilidade de reconhecimento das mulheres como iguais em direitos a capacidades.
} 
magistério, que Mary percebeu a necessidade de voltar o olhar para a educação feminina em busca da emancipação das mulheres (MORAES, 2016).

Entre seus colegas iluministas, Mary questionava a ausência do lugar de fala das intelectuais da época: "Quem fez do homem o juiz exclusivo, se a mulher compartilha com ele o dom da razão?” (WOLLSTONECRAFT, 2016, p. 19); bem como a existência de um sistema que forma, desde a base, mulheres para serem fracas e infelizes:

(...) a força e a utilidade são sacrificadas à beleza (...). Atribuo a causa desse florescimento estéril a um sistema de educação falso, extraído de livros sobre o assunto escritos por homens que, ao considerar as mulheres mais como fêmeas do que como criaturas humanas, estão mais ansiosos em torná-las damas sedutoras do que esposas afetuosas e mães racionais. O entendimento do sexo feminino tem sido tão distorcido por essa homenagem ilusória que as mulheres civilizadas do nosso século, com raras exceções, anseiam apenas inspirar amor, quando deveriam nutrir ambição mais nobre e exigir respeito por suas capacidades e virtudes. (WOLLSONECRAFT, 2016, p. 25, grifos nossos)

É importante perceber a denúncia quanto ao discurso naturalizante sobre uma suposta incapacidade da mulher para a vida pública. Para combater esse pensamento, Wollstonecraft se dedica a desconstruir todo o aparato argumentativo dos iluministas misóginos, em especial Rousseau.

Na obra Emílio, on Da Educação, o filósofo tece uma teoria sobre como devem se portar as mulheres, a partir de argumentos naturais, tais como a afirmação de que a mulher é "feita para obedecer" (ROUSSEAU, 1995, p. 440, grifos nossos) e que "todas as ideias das mulheres que não tenham a ver diretamente com assuntos de suas obrigações devem ser dirigidas para o estudo dos homens" (ROUSSEAU, 1995, p. 463, grifos nossos).

Mary Wollstonecraft (2016) ressalta que esse discurso naturalista acerca de um direito divino dos homens sobre as mulheres poderia ser facilmente desmascarado, em uma provocação ao que os iluministas questionavam na época sobre o pretenso direito divino dos reis absolutistas. Afinal, se era tão absurdo que os reis se mantivessem no poder, impondo uma dominação a um povo que se desejava livre, sob o argumento de um poder divino que lhes fora dado, da mesma forma estava o discurso naturalizante do patriarcado, que determinava um poder a ser exercido exclusivamente pelo homem, dentro da relação familiar, como se fosse determinado por Deus.

A mãe que deseja dar verdadeira dignidade de caráter à filha deve, sem fazer caso dos sarcasmos da ignorância, seguir um plano diametralmente oposto ao que Rousseau recomendou com todo o encanto enganoso da eloquência e dos sofismas filosóficos; porque sua eloquência torna plausíveis os absurdos, e suas conclusões dogmáticas confundem, sem convencer, os que não tem capacidade para refutá-las. (...). Desse modo, é muito fácil explicar a inclinação pelos trajes, evidente nas mulheres, sem supor que seja resultado de um desejo de agradar ao sexo do qual são dependentes. Em poucas palavras, o absurdo de presumir que uma menina é naturalmente coquete e que o desejo ligado ao impulso da natureza para propagar a espécie deveria aparecer mesmo antes que uma educação inapropriada o tivesse provocado prematuramente, ao acalentar a imaginação, é tão pouco filosófico que um observador tão sagaz quanto Rousseau não teria adotado se não tivesse sido acostumado a sacrificar a razão ao gosto pela singularidade, e a verdade, ao paradoxo (WOLLSTONECRAFT, 2016, p. 64-65, grifos nossos)

Nesse sentido, a filósofa feminista escancara o machismo do movimento iluminista e se dedica a mostrar que as razões para a manutenção das mulheres à sombra dos homens não faziam 
sentido. No entanto, mesmo com todo esforço praticado por Mary Wollstonecraft e Olympe de Gouges para refutar tais incoerências filosóficas, é mister lembrar que é sob a base de filósofos como Rousseau que está construída a filosofia política ocidental, que desde suas origens silencia o pensamento e o direito de mulheres a fazer parte das discussões políticas e filosóficas

Entre os séculos XIX e XX, quando o feminismo se torna uma luta formalmente organizada, com correntes de pensamentos e escolas dedicadas aos estudos da situação das mulheres na sociedade, o feminismo de Olympe De Gouges e Mary Wollstonecraft se torna base para a construção do feminismo liberal, porém, como alerta Miguel (2014), não se pode esquecer que ambas também trataram de outras questões, tais como a luta abolicionista e a representação política dos operários.

Por isso, mesmo aparentemente mais relacionadas à linha do feminismo liberal, o feminismo de De Gouges e Wollstonecraft se torna essencial de maneira geral, suas ideias são fontes de inspiração para a oposição à dominação masculina, que permeou (e ainda permeia) toda a construção dos Direitos Humanos no ocidente, em uma época em que muito se prometia à humanidade e pouco foi concedido às mulheres.

Para alguns grupos sociais, exigências trazidas pelo feminismo liberal, tais como os direitos individuais relacionados à liberdade, aparecem tardiamente e, algumas vezes, como fonte secundária de demandas, à exemplo das lutas do feminismo socialista, do feminismo indígena e do feminismo descolonial.

Percebe-se, pois, que dentro da lógica liberal há uma impossibilidade de realização de um direito das mulheres de modo pleno, já que tal lógica é constituída de forma que o sujeito central contemplado com a plena liberdade é o homem, denominado ser humano, porém instituído como aquele sujeito detentor do poder do falo e, consequentemente, da fala, como demonstrou Derrida (2013) em sua filosofia sobre o falogocentrismo. Nesse mesmo sentido, Andrea Nye reforça a ideia de que na defesa dos direitos humanos, o sujeito da fala e dos direitos é o homem:

O "homem" da teoria democrática não é o ser humano natural ou mesmo "homem natural"; em vez disso, é o homem na Europa industrializada do século XIX, separado dos laços feudais para estabelecer uma família ampliada, unidades econômicas independentes barganhando por uma decisiva vantagem econômica em meio à incontrolada e frequentemente destrutiva expansão da reprodução capitalista. Tudo o que a teoria liberal recomenda à feminista à guisa de estratégia, toda reforma legislativa e constitucional que ainda predomina como prática feminista em muitos países ocidentais, jamais poderá conseguir além de que as mulheres assumam o seu lugar (NYE, 1995, p. 42)

E, assim, as mulheres chegam ao século XXI, carregadas de supostas "garantias constitucionais" e até mesmo jus-humanistas, no plano internacional, porém permanecendo, em grande medida, no mesmo lugar de submissão, de controle e de sujeição às várias formas de violência, sem saída jurídica que garanta a elas o mínimo de liberdade ou, pelo menos, o direito de viver sem medo.

São muitas as liberdades e direitos conquistados historicamente pelas mulheres e suas lutas, porém cabe questionar se eles realmente são efetivos, já que o que vemos na prática é que a liberdade formal dada às mulheres pelo desenvolvimento tardio do chamado Direitos Humanos não se materializa na estrutura patriarcal a qual se está subjugada. A liberdade sexual, por exemplo, não garante às mulheres a segurança na escolha de seus parceiros, já que não as protege da violência 
doméstica, familiar ou mesmo pública. A liberdade para o trabalho não garante às mulheres o respeito no ambiente laboral, o acesso às posições que lhes cabe por equidade em relação aos homens e, novamente, não as protege da violência moral e sexual pelos seus colegas e superiores hierárquicos. A liberdade sobre seu corpo não garante às mulheres autonomia para decidir sobre ele. Mesmo após tantas conquistas, é possível dizer que elas permanecem não efetivas quando vemos a violência contra a mulher aumentar a cada dia, a desigualdade de salários e de oportunidades profissionais. Faz-se necessário, então, refletir sobre as origens do pensamento atual acerca dos Direitos Humanos e suas raízes na filosofia clássica.

\section{A EPISTEMOLOGIA FEMINISTA E A NECESSIDADE DE RESSIG- NIFICAÇÃO DOS DIREITOS HUMANOS.}

A dificuldade de muitos intelectuais em aceitar os feminismos como uma filosofia, uma epistemologia e, por isso, um consolidado fundamento e base de pesquisa, mostra a importância da contínua desconstrução feminista (com a licença da redundância) das nomeadas ciências.

A filosofia clássica dará o tom da forma como é construído o "conhecimento humano" tal qual conhecemos, se colocando como pautado pela objetividade e imparcialidade, porém ocultando sua formação enquanto discurso criado por homens e para homens. Nessa lógica, a filosofia estabelece uma ideia de universal e de humanidade, da qual irá surgir todo discurso relativo ao conhecimento e sua relação com o "homem”, que na prática não se concretiza.

Nesse discurso humanista essencialmente masculino, a mulher será o objeto de apropriação simbólica, ora relacionada como igual e, nesse sentido, negado a ela um lugar de fala com todas suas especificidades; ora como diferente, como um ser estranho ao universal, que merece tutela específica. Tudo isso a mercê dos interesses da lógica dominante.

É importante perceber que feminismo é plural e declaradamente contrário ao discurso objetivo da lógica patriarcal, intrínseca ao discurso humanista, atestando que os paradigmas de evidência serão relativos e dinâmicos, construídos histórica e coletivamente. Assim, o "feminismo surge como um contra-discurso que modifica as formas de ser e de dever ser dos comportamentos humanos em sociedade, refutando falsas posturas morais, assumidas como universais" (SANTOS, 2014, p. 130).

Uma das funções da epistemologia feminista é denunciar discursos neutros, que marcam a manutenção da dominação masculina, questionando "o valor do próprio conhecimento, de sua definição e obtenção social” (SANTOS, 2014, p. 131). Nesse sentido, a forma como uma teoria é apresentada é também o objeto de estudos das teorias feministas, observando a forma e o espaço que se habita e a posição dos corpos.

Os feminismos se (des)constroem a partir de "práticas da tomada de consciência, assim como no exercício da palavra e da relação que dão valor político à subjetividade, tomando-a como uma força capaz de mudar a realidade" (SANTOS,2014, p. 130). Isso significa que essa epistemologia acontece para e com o sujeito, em papel ativo, em possibilidades discursivas e distintivas de outras realidades. Nesse sentido, o sujeito da epistemologia feminista é sujeita e busca o seu espaço de fala, atenta e em constante luta política contra a redução de seu discurso como excêntrico ou como modismo.

Se é notório que o papel da sujeita filosófica é outro daquele determinado pela filosofia dominante, fica fácil compreender também que não existe filosofia feminista à maneira linguística 
dos homens, pois esse processo de ressignificação perpassa o momento de se lançar mão das outras linguagens (conceitos e sentidos) que escapam à linguagem patriarcal.

Se considerarmos ainda que a linguagem constrói o mundo, a realidade e até mesmo a racionalidade que nos move, praticar a filosofia feminista é romper com a racionalidade dada até então, produzindo um tipo de pensamento que é corporal, performativo e que joga para fora (expõe) toda forma de misoginia teórica, reverberando na forma como os sujeitos se relacionam com e no mundo.

Nessa epistemologia não é preciso dar um conceito fixo de "feminismo". Ele está em construção para cada uma, a partir da sua prática, ou seja, trata-se de um termo assumidamente de plurissignificação. A filosofia feminista é uma filosofia viva e, por isso, em desconstrução. Para tanto, é preciso partir de uma "auto-des-construção", ou seja, os feminismos devem ser frutos de uma autocrítica que produz efeitos performativos no mundo ao redor.

A teoria feminista é teoria crítica da sociedade que joga luz às questões invisíveis ou dissipadas por outras formas de pensamento impostas nessa sociedade. A crítica às ordens sociais préestabelecidas visa a desconstrução destas, para que se perceba os elementos nela inseridos por um discurso "naturalista". Nesse sentido, Amorós destaca que "a irracionalização de determinadas práticas e determinadas ordens de relações sociais é a condição mesma que faz possível que essas sejam visualizadas" (AMORÓS, 2008, p.13).

\footnotetext{
Eis que o feminismo demonstra-se como a grande voz que se realça diante das vozes de todas as mulheres em seu complexo processo de construção de identidades e de gênero, na diferença e na pluralidade cultural dos vários tempos do existir humano. Não se trata, contudo, de uma voz uníssona, mas composta de sons variados que instauram a produção de oposições pouco discretas como forma de criticar a matriz cultural patriarcal (SANTOS, 2014, p. 158)
}

Por fim, cumpre ressaltar aqui que o intuito desta apresentação da filosofia feminista não é fechá-la e reduzi-la ao ponto de vista aqui contido. Ao contrário. Trata-se de um trabalho que visa abrir caminhos e possibilidades. Os feminismos precisam ser vistos como correntes plurais de pensamento, que irão acontecer de formas variadas, de acordo com o grupo ou núcleo social de mulheres que fala ou do qual se fala e não se conforma aos tempos atuais, sendo necessário, portanto, o resgate histórico de vozes silenciadas, dando luz e a importância devida à pensadoras como Olympe De Gouges e Mary Wollstonecraft.

\subsection{Feminismo como desconstrução: dos direitos humanos à Justiça.}

Entendemos que o problema que envolve a discussão dos direitos das mulheres, enquanto direitos humanos, está ligada à capacidade de se concretizar a justiça igualitária, buscada pelas filósofas que tanto lutaram pela positivação desses direitos. De Gouges, Wollstonecraft e tantas outras feministas denunciaram a exclusão das mulheres do campo político e jurídico buscando não apenas o registro legal de seus direitos, mas sim a concretização de uma sociedade justa, com a desconstrução da mentalidade machista da sociedade ocidental.

Nesse sentido, devemos buscar o Direito enquanto instrumento de Justiça, sendo a Justiça, 
por sua vez, buscada fora da lógica masculina, isto é, Justiça como desconstrução ${ }^{10}$, como movimento, que acontece no desvelar da estrutura, mas não para alcançar o princípio fundante, a fim de que este movimento tenha um fim. E se é movimento no sentido derridiano, significa que a desconstrução não "é" o caminho para algo.

Derrida (2010), ao iniciar um seminário acerca da Justiça, começa questionando o público sobre em qual língua ${ }^{11}$ seria justo ele palestrar, tendo em vista que ele é francofônico, a audiência em sua maioria anglofônica e deveriam ainda considerar que demais espectadores poderiam necessitar do diálogo em outra linguagem.

Nessa linha, Derrida (2010) mostra, ao "optar" pela língua inglesa, o problema da palavra enforce, que está na base de discussão sobre a força que a lei produz ou deverá produzir em uma sociedade. Importante refletir, então, sobre os impactos das escolhas que fazemos, já que toda escolha pressupõe que outras alternativas foram negadas ou excluídas. Nesse sentido, permanecer nessa escolha de forma constante, colocando-a como o centro da racionalidade, impede a participação de outras possibilidades no debate.

Perceber a contradição da lei que deveria libertar, mas que foi construída to be enforced, isto é, que foi construída para ser imposta, ao promover a força que a sua criação lhe conduz, faz com que o filósofo caminhe no sentido de buscar entender o que permitirá a lei a produzir tal força. Qual seria então o fundamento da força da lei?

Derrida (2010), então, desconstrói a ideia de que a Justiça precisa de força para não ser demagogia, como sugeriu Pascal. O direito é construivel, sendo assim,

A desconstrução é justiça. É talvez porque o direito (que tentarei, portanto, distinguir regularmente da justiça) é construivel num sentido que ultrapassa a oposição da convenção da natureza, é talvez na medida em que ultrapassa essa oposição que ele é construivel - portanto desconstruivel e, ainda mais, que ele torna possível a desconstrução, ou pelo menos um exercício de uma desconstrução que, no fundo, trata sempre de questões de direito ou relativas ao direito (DERRIDA, 2010).

Por isso, a Justiça que visam os movimentos feministas na luta por direitos das mulheres não poderá ser encontrada de forma estática, nas leis criadas nos moldes falogocêntricos, sob pena de se formar em uma estrutura repousando em uma centralidade. E cabe ressaltar que esse movimento pode ser observado nas propostas de De Gouges e Wollstonecraft, e continua presente nos feminismos de todas as épocas.

É preciso que os feminismos se posicionem como movimento e se (re)movimentem toda vez que forem chamados para a justiça, para que não seja apenas teoria, que se perde ao se fixar e

10 "A palavra pode ser encontrada no Oxford English Dictionary, derivada do francês, para ser claro, mas, apesar disso, um termo inglês. De acordo com o OED, a primeira ocorrência escrita conhecida da palavra em inglês é em 1882. Aqui está a citação usada pelo Dictionary daquele ano: "Uma reforma das bases, que deve ser um trabalho de desconstrução". Desconstrução pressagia reforma, portanto, ela vem antes da reforma como sua base. Inaugurando ou iniciando uma atividade jurídica ou política de transformação, a desconstrução ilumina o fundamento, abre para a possibilidade de mudar a estrutura, a instituição, o discurso ou maquinaria organizada de pensamento e hábito. [...] enquanto a desconstrução não é nem um conceito nem uma coisa e não nomeia uma metodologia, não é também um significante chave" (WOLFREYS, 2007, p.47-49)

${ }^{11} \mathrm{~A}$ questão da língua é também um problema suscitado por Benjamim para tratar da palavra Gewalt (violência), conforme irá trabalhar Butler (2017) e mesmo Derrida (2010). Cabe anotar aqui que existe uma relação muito próxima acerca das duas problemáticas, facilmente perceptível quando se conclui nos dois autores que Direito é violência. 
reduz os direitos das mulheres a meros direitos construidos, se desprendendo da desconstrução, da justiça. Só assim acontecerá a pluralidade e a saída da lógica masculina que silencia e constitui a vida nua dos sujeitos femininos.

Dessa forma, qualquer análise do sistema jurídico proposto para enfrentar as injustiças contra os sujeitos femininos deve partir de um movimento de desconstrução, no qual participam as feministas de todas as épocas e que permite se reconstruir inclusive enquanto tema, na construção de saídas concretas, que nos liberte das origens excludentes do sistema jurídico vigente.

\section{CONSIDERAÇÕES FINAIS}

O ser feminino é ser-percebido e, por tanto, segue sendo compreendido pelo olhar masculino, ou seja, está imiscuído de passividade. Ao se discutir os feminismos enquanto teoria e ação política, pretende-se mostrar as diversas denúncias feitas por filósofas e sociólogas quanto à existência de uma imagem fantasiosa de um eterno feminino passivo, imposto pela dominação masculina.

Portanto, qualquer trabalho político, que vise contribuir com a resistência e a desconstrução dessa lógica patriarcal perversa, deverá ao menos atestar o processo de dominação dos sujeitos na relação binária feminino e masculino e possibilitar o caminho para a desconstrução dessa fantasia determinada à mulher para controle dos corpos. E, nesse sentido, é o que fazem as filósofas que coexistem e questionam a lógica política reafirmada pelo Iluminismo.

A proposta de revisitar a história nos ajuda a refletir sobre como as supostas evoluções na proteção das mulheres no cenário jurídico têm dificultado uma efetiva transformação. Sem criticar a contínua relação de dominação masculina que permeia os mais diversos aspectos da história da humanidade, em especial a lógica jurídica, todas as "conquistas" dos direitos das mulheres continuarão ineficazes por estarem difusas e não atacarem o cerne da questão, qual seja, a estrutura jurídica formada sob bases da lógica masculina.

Nesse sentido, retomar as ideias de De Gouges e Wollstonecraft, que já expunham a misoginia e colocavam em dúvida as razões modernas, é crucial, já que as desigualdades criticadas por elas seguem sem solução concreta, com a equidade de oportunidades e igualdade de direitos, ainda hoje, muito distantes de muitas mulheres.

\section{REFERÊNCIAS}

AMORÓS, Célia. Ressignificação Linguística. TIBURI, Márcia, VALLE, Bárbara. Mulheres, filosofia ou coisas do gênero. Santa Cruz do Sul (RS): EDUNISC, 2008.

BUTLER, Judith. Caminhos Divergentes. Judaicidade e crítica do sionismo. São Paulo: Boitempo. 2017

DALLARI, Dalmo. A Declaração dos Direitos da Mulher e da Cidadã por Olímpia de Gouges. São Paulo: Saraiva, 2016.

DE GOUGES. Olympe. Avante, Mulheres! Declaração dos Direitos da Mulher e da Cidadã e outros textos. Tradução e notas de Leandro Cardoso Marques da Silva; prefácio de Gláucia Fraccaro. São Paulo: Edipro, 2020.

DERRIDA, Jacques. Força de Lei. São Paulo: Editora WMF. Martins Fontes. 2010

DERRIDA, Jacques. Gramatologia. trad. Miriam Chnaiderman e Renato Janine Ribeiro. São Paulo: Perspectiva, 2013. 
HOBSBAWN, ERIC. A Era das Revoluções: 1789-1848. Rio de Janeiro: Paz e Terra, 1977.

MIGUEL, Luiz Felipe; BIROLI, Flávia. Feminismo e Política: uma introdução. São Paulo: Boitempo, 2014.

MORAES, Maria Lygia. Prefácio. In: WOLLSTONECRAFT, Mary. Reivindicações dos Direitos das MuIheres. São Paulo: Boitempo. 2016.

NEDERMAN, Cary J.; A Heretic Hiding in Plane Sight: The Secrete Story of Marsiglio oh Padua's Defensor Pacis in the Thought of Nicole Oresme. In: NEDERMAN, Cary J.; HUNTER lan; LAURSEN John Christian (orgs). Heresy In Transition: Transforming Ideas of Heresy in Medieval and Early Modern Europe. ASHGATE: England, 2005, p. 71-88

NOGUEIRA, Maria Simone M. Mística Feminina - Escrita e Transgressão. Revista Graphos, vol. 17, $n^{\circ}$ 2, UFPB/PPGL. 2015. p. 91-102

NYE, Andrea. Teoria Feminista e as Filosofias do Homem. Rio de Janeiro: Editora Rosa dos Tempos. 1995

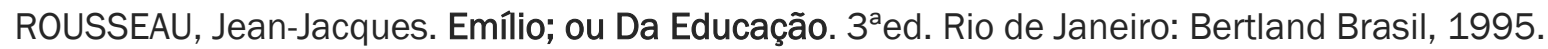

ROVERE, Maxime (Org.). Arqueofeminismo. Mulheres filósofas e filósofos feministas séculos XVII XVIII. São Paulo: N-1 Edições, 2019.

SANTOS. Magda G. O feminismo na história: suas ondas e desafios epistemológicos. In: BORGES, Maria de Lourdes; TIBURI, Marcia. Filosofia: Machismos e Feminismos. Florianópolis: ed. UFSC, 2014. p. 130 - 162.

SCOTT, Joan. Gênero: Uma categoria útil de análise histórica. Educação \& Realidade, Universidade Federal do Rio Grande do Sul, v.20, n.2, p. 71-99, 1995. Disponível em: https://seer.ufrgs.br/educacaoerealidade/article/view/71721/40667. Acesso em: 06 de out. 2020.

TARRANT, Shira. When sex became gender. New York: Routledge. 2006

WOLFREYS, Julian. Compreender Derrida, Petrópolis: Editora Vozes, 2007.

WOLLSTONECRAFT, Mary. A Reivindicação dos Direitos das Mulheres. São Paulo: Boitempo, 2016. 